\title{
The Drivers behind Gas Market Liberalization: Diversity of Gas Sources, Market Structure and Gas Prices
}

\author{
Iweta Opolska $^{1} \&$ Michał Jakubczyk ${ }^{2}$ \\ ${ }^{1}$ Faculty of Economic Sciences, University of Warsaw, Warsaw, Poland \\ ${ }^{2}$ Institute of Econometrics, Warsaw School of Economics, Warsaw, Poland \\ Correspondence: Iweta Opolska, Faculty of Economic Sciences, University of Warsaw, Warsaw, Poland. Tel: \\ 48-506-287-852. E-mail: iweta.opolska@gmail.com
}

\author{
Received: May 14, 2013 \\ Accepted: May 31, 2013 \\ Online Published: June 14, 2013 \\ doi:10.5539/ibr.v6n7p14 \\ URL: http://dx.doi.org/10.5539/ibr.v6n7p14
}

\begin{abstract}
This paper studies how European Union members' individual gas market characteristics, i.e. source diversification, incumbent firms' market share and gas prices, measured at the start of liberalization process, influenced the full market opening timetable. A linear regression model is proposed with the time lag to the introduction of liberalization since 1998 (the first EU gas directive) as a dependent variable and the market characteristics as independent variables. The model is applied to cross-sectional data for 13 European countries. The results confirm the statistically significant impact of the market characteristics on the liberalization schedule. Our model explains $90 \%$ variation in the dependent variable. The more concentrated initial gas import structure and the higher import dependence were, the later the full market opening was scheduled. The more competitive gas market structure and the higher the average gas prices at the start of deregulation were, the sooner the gas sector was open to competition. The conclusions of the paper can be important for a better understanding of the liberalization process in the European Union and for application of EU deregulation experience to other countries.
\end{abstract}

Keywords: gas, liberalization, competition, source diversification, deregulation, gas prices

\section{Introduction}

\subsection{European Gas Market Liberalization}

The liberalization process of the natural gas industry in the European Union is celebrating its fifteenth anniversary in the year 2013. It started in 1998 with the introduction of the first gas directive, which was amended twice since then: in 2003 (the second gas directive) and 2009 (the third gas directive).

The gas sector liberalization in the EU was triggered by the deregulation progress in the US and UK but also the fact that Europe was becoming increasingly dependent on external gas suppliers. The liberalization was intended to be a response to Europe's import dependency, as it meant to create a single, competitive and secured gas market within its borders. Thus, the European gas policy was based on three pillars: single pan-European energy market, free market paradigm and security of supply. Indeed, a competitive and integrated European market should imply a better ability to respond to external supply shocks and should benefit consumers by lowering energy prices.

Fifteen years into the process we can see how differently the EU members dealt with restructuring of their gas industries, despite the common guidelines delineated by the gas directives. The European gas policy left the countries some autonomy to choose their own paths within the predefined legislative framework. One important parameter of this framework was opening of gas markets to competition. Market opening was defined as providing 'eligible' customers, i.e. "customers who are free to purchase gas from the supplier of their choice", the legal capacity to contract for, or to be sold, natural gas. The first gas directive laid down lenient conditions for market opening. It defined the lowest threshold to only be $20 \%$ of the total annual gas consumption of the national gas market with no deadline for the full market opening. Five years later the second gas directive accelerated natural gas market liberalization and bound the EU members to fully open their gas market by 1 July 2007. Three out of fifteen EU members derogated from this obligation: Finland, Greece and Portugal, as they were either recognized as emerging gas markets (less than 10 years of gas operations), like Greece or Portugal, 
or too isolated from the rest of the European market (Finland).

Within the 10 year time that the member states were granted to fully open gas markets, there were some primus inter pares (Germany, United Kingdom) that pioneered in fostering liberalization since 1998 and thelaggards profiting from derogations. What was the reason behind the different advancement of gas market liberalization among the EU members? What differentiated the countries and caused some to be reluctant to changes while others inclined to make them as soon as possible? This article attempts to answer the questions.

\subsection{Literature Review}

The literature on energy sector liberalization is vast but leaves the above-mentioned questions open. Most researchers explore the impact of liberalization either on gas prices, e.g. Slaba, Gapko and Klimesova (2013), Kratena (2004, 2011), Brau, Doronzo, Fiorio and Florio (2010), or on security of supply, like Joskow (2005), Wright (2005), von Hirschhausen (2008), Pollitt (2008).Others provide case studies of a single country's liberalization process, e.g. Stern (1997) in Great Britain, García (2006) in Spain, Cetin and Oguz (2007) in Turkey, Słupik (2012) in Poland.

Some of the authors stress the influence of country's individual characteristics on the liberalization method and outcome. Slaba, Gapko and Klimesova (2013) point out that individual country's import dependency, initial market structure, legal and institutional conditions determine results of the liberalization process. A starting point of the Cetin's and Oguz's (2007) analysis of the Turkish gas market reform is the observation that source diversity with a higher number of suppliers is a crucial part of competition in the natural gas market. They also suggest that Turkey's dependency on Russia for natural gas can trigger an energy crisis, which in turn brings conflicts between the government and the regulatory authority on policy issues. It increases the costs of the transition to a competitive market. Joskow (2005) formulates a base question for future research: what changes in industry structure and regulatory mechanisms are needed to facilitate the introduction of competition into one or more segments of regulated industries.

Hiroaki (2009) finds a relationship between electricity prices and government's willingness to adopt liberalization models: higher energy prices are one of the driving forces for governments to adopt deregulation. However, liberalization in the power sector does not necessarily reduce electricity prices. In fact, contrary to expectations, there is a tendency for the price to rise in every market modeled.

The research by Hiroaki (2009) has not been extended to the natural gas market so far. Nor have the contributing factors for government's enthusiasm for gas market opening been examined. This paper is an attempt to fill the gap by focusing on the conditions that influenced the EU members' timetable for a gas market opening. We seek to prove that the countries with a more diversified gas portfolio, higher gas prices and a less concentrated market structure at the start of the liberalization tend to introduce deregulation sooner. A positive verification of this hypothesis could help to better understand why some energy policies are doomed to be less successful if not enough emphasis is put on key market characteristics.

\section{Method}

This section describes the basic ingredients of a statistical model that we develop to analyze the influence of initial gas market characteristics on the liberalization progress.

We perform a regression analysis with three independent variables to assess the relationship:

$$
\text { Liber_lag }_{i}=\beta_{0}+\beta_{1} \times H H I_{-} a d j_{-} 98_{i}+\beta_{2} \times \text { Incumb_share } 98_{i}+\beta_{3} \times \text { Price_ave }_{i}+\varepsilon_{i}
$$

Where $i$ is an index denoting a given country, Liber_lag $i$ is the number of years it took to open the gas market since 1998, HHI_adj_98 ${ }_{i}$ is Herfindahl-Hirschman Index for gas import structure in the year 1998, adjusted for domestic gas production, Incumb_share $98_{i}$ is incumbent firm's market share in the wholesale gas market in the year 1998, Price_ave $i$ is anaverage gas price for domestic and industrial clients in EUR per GJ in the years 1998-1999 and $\varepsilon_{i}$ is the error-term. This particular specification was statistically verified to be proper (the results follow), and no alternative models/variable transformations are needed.

\subsection{Variables}

\subsubsection{Gas Market Opening Time Lag (Liber_lagi $)$}

The dependent variable denotes the time difference between the year 1998 and the first year of gas market full opening. It can be interpreted as a proxy of government's attitude towards liberalization, as the choice of the final date for gas market opening was subject to individual jurisdiction. The longer is the time till gas market opening the more time the government takes to introduce competition to the gas sector. However, the European Commission imposed the deadline for the gas market opening to be on 1 July 2007. A member could apply for 
derogation if certain conditions, e.g. market isolation or maturity, were satisfied. In case of Finland the derogation period was extended with no exact deadline specified. As long as Finland only has one main supplier of natural gas and is not connected to the European gas network, it is not bound by the EU gas law. Since the gas market opening time lag has been undefined, the data on Finland's Liber_lag $g_{i}$ is windsorized (model 1) or dropped (model 2).

\subsubsection{Gas Sourcing Structure (HHI_adj_98 ${ }_{i}$ )}

Herfindahl-Hirschman Index is used as an indicator of the concentration of country's gas import structure. It is calculated as a sum of squared exporter countries' share in the importer's gas portfolio, regardless of the transportation means used. For example, Spain imports gas from Algeria both via a pipeline system and a LNG terminal, and Algeria's share in Spain's gas import portfolio is a sum of pipeline and LNG volumes divided by total Spain's import volume. The gas import portfolio is based on country-to-country trades, not on contracting party information. Both approaches, however, should render coherent results, as top gas suppliers to Europe are single representatives of their countries.

To account for the fact that own gas production decreases import dependency and increases flexibility in devising country's energy policy, the HHI has been adjusted as follows:

$$
\text { HHI_adj_ } 98_{i}=H H I_{-} 98_{i} \times\left(100 \%-\text { gas }_{-} \text {production_ } 98_{i}\right)
$$

Wheregas_production_98 ${ }_{i}$ is domestic gas production's share in the total consumption in 1998.

We expect the relationship between the HHI and the dependent variable to be positive. The stronger dependence on a single gas supplier, the more opportunistic attitude towards restructuring of the gas sector is observed.

\subsubsection{Incumbent Firm's Share in the Gas Market (Incumb_share $98_{i}$ )}

We calculate the incumbent company's market share in the domestic gas industry in the year 1998 to proxy for the internal market structure at the eve of liberalization. Two segments of the trading on the gas market can be distinguished: wholesale and retail. The wholesale level typically involves buying gas from upstream gas companies (external suppliers or domestic gas producers) and reselling it to retail distributors. The retail market is defined as supplying gas to end consumers. The liberalization process starts from the upper level of the value chain - from the wholesale market.

At the early stage of the market liberalization the incumbent that buys gas from upstream firms is usually engaged in the retail market as well, thus, little or no reselling takes place. Sometimes the retail level of the gas market is dominated by a few regional monopolies and, thus, calculating their market share gives a false impression of competition. Consequently, the Incumb_share $98_{i}$ variable represents leading company's market share at the wholesale level.

If there is already some competition in place, even in a dominated industry, the market players and customers are likely to be better equipped for the liberalization process and, therefore, the government may be less resistant to fully open the market.

\subsubsection{Average Gas Price (Price_ave ${ }_{i}$ )}

One of the key impulses for liberalization is a desire to lower gas prices. If gas prices are already relatively low, the motivation weakens and, instead, an anxiety for price convergence that could push domestic gas costs up may take its place.

The gas price variable is averaged for all domestic and industry customers over two years (1998 and 1999) in order to increase available information. If there is a missing value on the year 1998 (Denmark), then the available 1999 data is applied. In case of information availability on both years, the average value is calculated. The averaging does not change the informational content of the variable due to small and correlated price movements between the two years.

The gas price is measured in EUR / ECU per GJ. The currency exchange conversion is executed according to the Eurostat methodology.

\subsection{Data}

The theoretical model is applied to the cross-sectional data collected for the15 European countries that had already been European Union members when the first gas directive went into force (1998). Two of the countries (Portugal, Greece) have to be excluded from the analysis due to missing data on gas prices. Our final sample consists of 13 countries, i.e. Austria, Belgium, Denmark, Finland, France, Germany, Italy, Ireland, Luxembourg, Netherlands, Spain, Sweden, and United Kingdom. The choice of the European members allows us to analyze 
cases with diverse market characteristics on one hand, and common policy goals on the other hand. In 1998 all countries, besides United Kingdom, were at the outset of the gas market deregulation. It gives a unique opportunity to study a comparable set of data.

We utilize information provided by national energy regulators papers to assess the time lag between the year 1998 and the first year when the national gas market became fully open. We also use energy regulators' websites and papers, and corporate annual reports to compute incumbent's market share. In some cases it has to be indirectly deducted from a more general description of the market. The information on exporter country's market share in a national gas sourcing portfolio is derived from yearly BP Statistical Reviews of World Energy of 1999, where information on gas trades (on a contractual basis) between countries is provided. Finally, we make a use of Eurostat database to derive average gas prices for the EU countries, presented in Euro / ECU currency per GJ.

The statistical software used in the analysis is IBM SPSS version 21.0.

Table 1 summarizes basic data statistics.

Table 1. Descriptive statistics of the variables

\begin{tabular}{lllll}
\hline & HHI_adj_98 & Incumb_share_98 & Price_ave & Liber_lag \\
\hline Mean & 0.441 & 0.887 & 5.452 & 6.46 \\
Median & 0.315 & 1.000 & 5.455 & 6.00 \\
Minimum & 0.000 & 0.250 & 4.500 & 0 \\
Maximum & 1.000 & 1.000 & 6.300 & 13 \\
Std. Deviation & 0.373 & 0.219 & 0.606 & 3.76 \\
Skewness & 0.489 & -2.465 & -0.242 & -0.37 \\
Kurtosis & -0.987 & 6.225 & -1.109 & -.067 \\
\hline
\end{tabular}

As shown in Table 1, the HHI_adj_98 variable spans a whole range of values between 0 and 1, with a mean of 0.441. At the extreme low there are countries with high domestic gas production like UK, Denmark, and Netherlands. The maximum HHI_adj_98 values are observed in the countries with no gas production and single gas supplier, like Finland, Luxembourg and Sweden. The Incumb_share_98 statistics indicate the EU gas markets were predominantly of a monopolistic structure, with a mean of 0.887 and half of the countries with monopolies and no own gas sources (HHI equal to 1). In the most liberalized gas market - United Kingdom -the British Gas' share was around 25\% in 1998. The Price_ave variable resembles normal distribution, with the mean of 5.452 EUR/GJ close to the median of $5.455 \mathrm{EUR} / \mathrm{GJ}$. The lowest average gas prices were observed in Finland, Netherlands and Belgium. On the contrary, Germany and Italy stood out as countries with the most expensive gas. The mean time lag between gas market opening and 1998 year was around 6 years in the sample. Most analyzed EU countries scheduled gas market opening at the deadline year of 2007 . Two countries opened their gas markets already in 1998 - UK and Germany. Finland was granted derogation.

\section{Results}

The statistical analysis is performed to find the relationships between the time lag in gas market opening since 1998 and three market characteristics, i.e. gas sourcing diversification, wholesale market concentration and average gas prices at the start of the European gas sector liberalization process.

\subsection{Correlation Analysis}

The table 2 presents Spearman's correlation matrix. It proves to support the hypothesized relationships between the response and its explanatory variables.

Table 2. Spearman's correlation matrix

\begin{tabular}{llll}
\hline & HHI_adj_98 & Incumb_share_98 & Price_ave \\
\hline Liber_lag & $0.508^{*}$ & $0.841^{* * *}$ & $-0.624^{* *}$ \\
Sig. (2-tailed) & 0.076 & 0.000 & 0.032 \\
HHI_adj_98 & & 0.418 & -0.089 \\
Sig. (2-tailed) & & 0.155 & 0.773 \\
Incumb_share_98 & & & -0.341 \\
Sig. (2-tailed) & & & 0.254 \\
\hline
\end{tabular}

Notes: * significant at the 0.10 level. ${ }^{* *}$ significant at the 0.05 level. ${ }^{* *}$ significant at the 0.01 level (2-tailed). 
As indicated in the table 2 , all three independent variables show a statistically significant relationship with the dependent at least at the $10 \%$ level. The Spearman's correlation coefficients between the market opening time lag and both the gas sourcing structure and incumbent's market share in 1998 are positive, as expected. The gas prices and the lag exhibit a negative relationship, in line with expectations too.

The correlations among the independent variables are not statistically significant, which suggests that the observatory variables are independent and multicollinearity should not be a problem.

\subsection{Regression Analysis Results}

The results of the multivariate regression analysis are presented in the tables 3 and 4 . As model 1 the analysis outcome including Finland's data is presented. As model 2 the results of regression without Finland are shown.

Table 3. Model results

\begin{tabular}{lll}
\hline Model & R Square & Adjusted R Square \\
\hline 1 (with FIN) & 0.897 & 0.862 \\
2 (without FIN) & 0.874 & 0.827 \\
\hline
\end{tabular}

The model is statistically significant in both cases, with p-value (F) of 0.0001 (model 1) and p-value (F) of 0.0006 (model 2). The R square indicates that as much as $89,7 \%$ (model 1) or $87,4 \%$ (model 2) of the variation of the dependent variable is explained by the variations of the independent variables.

In search for scale effects we also extend the model to include national gas consumption (1998) variable, but its coefficient is not significant (p-value of 0.667 ) and the R squared of the extended model is hardly changed (0.899 vs. 0.897).

Table 4. Coefficients

\begin{tabular}{|c|c|c|c|c|c|}
\hline \multirow{2}{*}{$\begin{array}{l}\text { Model } 1 \\
\text { (with FIN) }\end{array}$} & \multicolumn{2}{|c|}{ Unstandardized Coefficients } & Standardized Coefficients & \multirow[t]{2}{*}{$\mathrm{t}$} & \multirow[t]{2}{*}{$\mathrm{p}$-value } \\
\hline & $\mathrm{B}$ & Std. Error & Beta & & \\
\hline (Constant) & 13.327 & 4.630 & & 2.878 & 0.018 \\
\hline HHI_adj_98 & 3.904 & 1.241 & 0.372 & 3.145 & 0.012 \\
\hline Incumb_share_98 & 9.071 & 2.162 & 0.509 & 4.195 & 0.002 \\
\hline Price_ave & -3.037 & 0.711 & -0.471 & -4.272 & 0.002 \\
\hline \multirow{2}{*}{$\begin{array}{l}\text { Model } 2 \\
\text { (without FIN) }\end{array}$} & \multicolumn{2}{|c|}{ Unstandardized Coefficients } & Standardized Coefficients & $\mathrm{t}$ & $\mathrm{p}$-value \\
\hline & $\mathrm{B}$ & Std. Error & Beta & & \\
\hline (Constant) & 9.822 & 5.156 & & 1.905 & 0.093 \\
\hline HHI_adj_98 & 2.924 & 1.398 & 0.304 & 2.092 & 0.070 \\
\hline Incumb_share_98 & 9.634 & 2.166 & 0.652 & 4.553 & 0.002 \\
\hline Price_ave & -2.443 & 0.814 & -0.406 & -3.002 & 0.017 \\
\hline
\end{tabular}

The coefficients of gas sourcing structure, incumbent's market share and average gas prices all support the correlation analysis results and reinforce the stated hypotheses about their relationships with the liberalization time lag. The HHI_adj_98 variable is positively associated to the Liber_lag and the association is statistically significant at 0.05 level (model 1) or at 0.1 level (model 2). Similarly, there is a positive and statistically significant at $1 \%$ level relationship between Incum_share_98 and the dependent variable. The Price_ave variable is negatively related to the Liber_lag at the $2 \%$ level of significance.

The model is statistically tested and proven robust with respect to the following problems:

- specification - RESET test, $\mathrm{p}$-value $=0.696$ for model 1 and $\mathrm{p}$-value $=0.149$ for $\operatorname{model} 2$,

- heteroscedasticity - White test, $\mathrm{p}$-value $=0.919($ model 1$)$ or $0.985($ model 2$)$; Breusch-Pagan test, $\mathrm{p}=0.823$ (model 1$)$ or $\mathrm{p}=0.990(\operatorname{model} 2)$,

- multicollinearity - small Variance Inflation Factors in both models (less than 1.5),

- normality of residuals - Doornik-Hansen test, $p$-value $=0.975($ model 1$)$ or $p$-value $=0.768(\operatorname{model} 2)$. 


\section{Discussion}

The results support the supposition that individual pre-liberalization gas market characteristics of the EU members, i.e. gas portfolio diversification, incumbent firm's market share and gas prices, significantly influenced the full market opening timetable. The obligation to introduce full liberalization to national gas markets by the year 2007 was imposed on the EU members first in 2003. At that time, 5 of the 13 analyzed countries had already forced full market opening, next 2 members followed in 2004 (see the table 5). This fact reinforces the assumption that the EU15 has had enough autonomy to individually form their gas policy and the dependent variable, though limited by the EU gas directive, may have been influenced by other factors. The three market characteristics prove to have a significant impact on the decision to make all customers eligible.

Table 5. Gas market opening by European Union members

\begin{tabular}{lllllllllll}
\hline Country & $\mathbf{1 9 9 8}$ & $\mathbf{1 9 9 9}$ & $\mathbf{2 0 0 0}$ & $\mathbf{2 0 0 1}$ & $\mathbf{2 0 0 2}$ & $\mathbf{2 0 0 3}$ & $\mathbf{2 0 0 4}$ & $\mathbf{2 0 0 5}$ & $\mathbf{2 0 0 6}$ & $\mathbf{2 0 0 7 - 1 2}$ \\
\hline Austria & $0 \%$ & $0 \%$ & $49 \%$ & $50 \%$ & $100 \%$ & $100 \%$ & $100 \%$ & $100 \%$ & $100 \%$ & $100 \%$ \\
Belgium & $0 \%$ & $0 \%$ & $47 \%$ & $47 \%$ & $59 \%$ & $83 \%$ & $83 \%$ & $90 \%$ & $90 \%$ & $100 \%$ \\
Denmark & $0 \%$ & $0 \%$ & $30 \%$ & $30 \%$ & $35 \%$ & $35 \%$ & $100 \%$ & $100 \%$ & $100 \%$ & $100 \%$ \\
Finland & $0 \%$ & $0 \%$ & $0 \%$ & $0 \%$ & $0 \%$ & $0 \%$ & $0 \%$ & $0 \%$ & $0 \%$ & $0 \%$ \\
France & $0 \%$ & $0 \%$ & $20 \%$ & $20 \%$ & $20 \%$ & $37 \%$ & $73 \%$ & $73 \%$ & $73 \%$ & $100 \%$ \\
Germany & $100 \%$ & $100 \%$ & $100 \%$ & $100 \%$ & $100 \%$ & $100 \%$ & $100 \%$ & $100 \%$ & $100 \%$ & $100 \%$ \\
Ireland & $72 \%$ & $72 \%$ & $72 \%$ & $77 \%$ & $77 \%$ & $84 \%$ & $84 \%$ & $84 \%$ & $84 \%$ & $100 \%$ \\
Italy & $0 \%$ & $0 \%$ & $0 \%$ & $65 \%$ & $65 \%$ & $100 \%$ & $100 \%$ & $100 \%$ & $100 \%$ & $100 \%$ \\
Luxembourg & $0 \%$ & $0 \%$ & $0 \%$ & $46 \%$ & $46 \%$ & $61 \%$ & $78 \%$ & $78 \%$ & $78 \%$ & $100 \%$ \\
Netherlands & $0 \%$ & $0 \%$ & $45 \%$ & $45 \%$ & $60 \%$ & $60 \%$ & $100 \%$ & $100 \%$ & $100 \%$ & $100 \%$ \\
Spain & $46 \%$ & $60 \%$ & $67 \%$ & $72 \%$ & $79 \%$ & $100 \%$ & $100 \%$ & $100 \%$ & $100 \%$ & $100 \%$ \\
Sweden & $0 \%$ & $0 \%$ & $0 \%$ & $47 \%$ & $47 \%$ & $50 \%$ & $50 \%$ & $95 \%$ & $95 \%$ & $100 \%$ \\
UK & $100 \%$ & $100 \%$ & $100 \%$ & $100 \%$ & $100 \%$ & $100 \%$ & $100 \%$ & $100 \%$ & $100 \%$ & $100 \%$ \\
\hline
\end{tabular}

The diversity of gas sources, especially if a country is highly import dependent, confirms to be a significant contributing factor that accelerates gas market opening. It gives the government more flexibility to push the liberalization reforms forward, as a risk of supply interruptions is more mitigative. The incumbent firm is more likely to adjust the contracts to the new gas sector model, according to which it has to share the market with new entrants and more gas is traded on the spot market. Furthermore, it is less exposed to a loss of the bargaining power with the dominant supplier, as there are alternative suppliers in place ready to take over the major supplies. Moreover, a less concentrated gas import structure is usually a result of a well-developed gas infrastructure, in particular availability of diverse gas interconnectors. An extensive transmission system with its multiple connection points to neighboring system supports the liberalization process to a great extent by providing the necessary infrastructure to new entrants.

The initial market structure is also confirmed to have contributed to the decision on the gas market opening by the analyzed EU members. The more monopolistic was the market structure in the year 1998, the later the opening to competition took place. If there are already some competitors present, they may put a pressure on the government to open the gas market sooner, especially if their claims are supported by the EU energy policy. Moreover, the initial less concentrated market structure may indicate lower barriers to entry the market, which can be a result of some measures already taken by a government or regulator to foster competition.

Similar to finding by Hiroaki (2009) for a power sector, our results support the theory that higher gas prices induce governments to adopt government earlier than lower gas prices do. It can be explained twofold. Firstly, countries of relatively lower priced gas gain less of potential price reduction resulting from liberalization, thus, they have less motivation to open the gas market. Additionally, the government may fear that a liberalized market would bring price convergence with countries of higher gas prices. Consequently, the countries with higher gas prices anticipate gaining more from liberalization and the higher prices provide a better stimulus for new entrants.

This research adds to the prior literature by providing empirical evidence that gas sector initial attributes, i.e. diversity of gas sources, market structure and gas prices, influenced the EU members' timetable for gas market opening. The conclusions that can be drawn from the evidence are of theoretical and practical nature. Firstly, to our best knowledge this paper is the first attempt to systematically approach the subject of time lag in liberalization among different countries. Secondly, the outcome implies what conditions are important for 
government in order to exhibit more willingness to restructure the gas sector.

However, there are some limitations of this study and the results should be treated with caution. First of all, the number of observations is quite limited due to need to keep the cases comparable, like the EU-15 members, and the missing data. Secondly, focus on the EU only may reduce a direct applicability of the results to other regions of the world. Notwithstanding the above limitations, the results are sufficiently interesting to justify an extension of such are search to a larger sample size and to other economies. Additionally, in the future it could be worth examining how the analyzed market characteristics influence not only liberalization timetable but also the competition measures.

\section{References}

Brau, R., Doronzo, R., Fiorio, C. V., \& Florio, M. (2010). EU Gas Industry Reforms and Consumers' Prices. The Energy Journal, 31, 167-182. http://dx.doi.org/10.5547/ISSN0195-6574-EJ-Vol31-No4-8

Breusch, T. S., \& Pagan, A. R. (1979). Simple test for heteroscedasticity and random coefficient variation. Econometrica, 47, 1287-1294. http://dx.doi.org/10.2307/1911963

Cetin, T., \& Oguz, F. (2007). The reform in the Turkish natural gas market: A critical evaluation. Energy Policy, 35, 3856-3867. http://dx.doi.org/10.1016/j.enpol.2007.01.008

Directive 2003/55/EC of the European Parliament and of the Council of 26 June 2003 concerning common rules for the internal market in natural gas and repealing Directive 98/30/EC. (2003). Retrieved from http://eur-lex.europa.eu/LexUriServ/LexUriServ.do?uri=CELEX:32003L0055:EN:NOT

Directive 2009/73/EC of the European Parliament and of the Council of 13 July 2009 concerning common rules for the internal market in natural gas and repealing Directive 2003/55/EC. (2009). Retrieved from http://eur-lex.europa.eu/LexUriServ/LexUriServ.do?uri=CELEX:32009L0073:EN:NOT

Directive 98/30/EC of the European Parliament and of the Council of 22 June 1998 concerning common rules for the internal market in natural gas. (1998). Retrieved from http://eur-lex.europa.eu/LexUriServ/LexUriServ.do?uri=CELEX:31998L0030:EN:NOT

Garcia, L. A. R. (2006). The liberalisation of the Spanish gas market. Energy Policy, 34, 1630-1644. http://dx.doi.org/10.1016/j.enpol.2004.12.013

Hiroaki, N. (2009). Electric power sector reform liberalization models and electric power prices in developing countries. An empirical analysis using international panel data. Energy Economics, 31, 463-472. http://dx.doi.org/10.1016/j.eneco.2008.12.004

Joskow, P. (2005). Regulation and deregulation after 25 years: lessons learned for research in industrial organization. Review of Industrial Organization, 26, 169-193. http://dx.doi.org/10.1007/s11151-004-7295-6

Kratena, K. (2004). Evaluierung der Liberalisierung des österreichischen Energiemarktesausmakroökonomischer Sicht. WIFO-Monatsberichte, 1, 837-843.

Lise, W., \& Kruseman, G. (2008). Long-term price and environmental effects in a liberalised electricity market. Energy Economics, 30, 230-248. http://dx.doi.org/10.1016/j.eneco.2006.06.005

Pollitt, M. (2008). The arguments for and against ownership unbundling of energy transmission networks. Energy Policy, 36, 704-713. http://dx.doi.org/10.1016/j.enpol.2007.10.011

Ramsey, J. B. (1969). Tests for Specification Errors in Classical Linear Least Squares Regression Analysis. Journal of the Royal Statistical Society, 31, 350-371.

Slaba, M., Gapko, P., \& Klimesova, A. (2013). Main drivers of natural gas prices in the Czech Republic after the market liberalisation. Energy Policy, 52, 199-212. http://dx.doi.org/10.1016/j.enpol.2012.08.046

Stupik, S. (2012). Barriers to Developing Competition in the Polish Electricity and Gas Market. International Business Research, 5, 160-171. http://dx.doi.org/10.5539/ibr.v5n8p160

Stern, J. P. (1997). The British gas market 10 years after privatization: A model or a warning for the rest of Europe? Energy Policy, 25, 387-392. http://dx.doi.org/10.1016/S0301-4215(97)00021-9

Von Hirschhausen, C. (2008). Infrastructure, regulation, investment and security of supply: A case study of the restructured US natural gas market. Utilities Policy, 16, 1-10. http://dx.doi.org/10.1016/j.jup.2007.08.001

White, H. (1980). A Heteroskedasticity-Consistent Covariance Matrix Estimator and a Direct Test for Heteroskedasticity. Econometrica, 48, 817-838. http://dx.doi.org/10.2307/1912934 
Wright, P. (2005). Liberalisation and the security of gas supply in the UK. Energy Policy, 33, 2272-2290. http://dx.doi.org/10.1016/j.enpol.2004.04.022

\section{Copyrights}

Copyright for this article is retained by the author(s), with first publication rights granted to the journal.

This is an open-access article distributed under the terms and conditions of the Creative Commons Attribution license (http://creativecommons.org/licenses/by/3.0/). 